\title{
A DIMENSÃO GESTIONÁRIA DO TRABALHO E O DEBATE DE NORMAS E VALORES NO TELEATENDIMENTO
}

\author{
THE MANAGERIAL DIMENSION OF THE WORK AND THE DEBATE ON STANDARDS AND VALUES \\ IN TELEMARKETING
}

\author{
Simone Santos Oliveira ${ }^{1}$ \\ Jussara Cruz de Brito ${ }^{2}$
}

Resumo Evidenciar a 'dimensão gestionária' na atividade de teleatendimento é o principal objetivo deste artigo. A perspectiva ergológica entende o trabalho como encontro singular com uma tarefa a ser realizada, que com suas variabilidades sempre possui uma gestão a ser feita pelos trabalhadores(as). Essa gestão está intimamente relacionada à capacidade de definir e produzir a saúde e a doença. Para apreender a complexidade e a singularidade do trabalho em teleatendimento, para além do visível e quantificável das prescrições, buscou-se a utilização da técnica de Instruções ao Sósia e dos Encontros sobre o Trabalho, na perspectiva de propiciar uma reflexão e um discurso sobre o trabalho pelos(as) trabalhadores(as). As renormatizações foram observadas em outro uso das prescrições: pausas, script e voz, através dos quais os(as) operadores(as) imprimem sua marca. O valor do emprego se contrapõe às repercussões negativas para a saúde, o adoecimento e o sofrimento, com controle rigoroso do espaço, do tempo e do comportamento. Conclui-se que a consideração da 'dimensão gestionária', vista na sua singularidade, deve ser reconhecida pelos(as) próprios(as) trabalhadores(as), profissionais da saúde e pesquisadores, como elemento fundamental para a prevenção dos adoecimentos e para a promoção da saúde.

Palavras-chave teleatendimento; saúde do trabalhador; ergologia.
Abstract The principal objective of this study is to highlight the 'managerial dimension' in telemarketing activity. The ergological perspective understands work as a unique encounter with a task to be performed, which, within its variability, always requires management by the workers. This management is intimately related to the capacity to define and produce illness and health. In order to grasp the complexity and singularity of working in telemarketing, beyond that which is visible and quantifiable in the prescriptions, the use of the Instructions for the Double technique and Meetings about Work was tried, with a view to providing the workers with a reflection upon and a discourse about the work. Re-standardizations were observed in another use of the prescriptions: pauses, script and voice, by means of which telemarketers make their mark. The value of the jobin contrasts to the negative repercussions on health, falling ill and suffering, with close monitoring of behavior, time and space. The conclusion is that health professionals, researchers and the workers themselves must acknowledge the considering of the 'managerial dimension', in its singularity, as a fundamental element for preventing illnesses and promoting health.

Keywords telemarketing; occupational health; ergology. 
O conceito de trabalho varia de uma sociedade para outra e também, historicamente, no interior de uma mesma sociedade. Dependendo da perspectiva e do que se entende por trabalho, pode-se perceber uma grande diversidade de práticas que se desenvolvem dentro de estruturas sociais que lhe dão significação. Nas sociedades industriais, por exemplo, o conceito de trabalho - historicamente datado e enquadrado pela produção econômica - aponta duplamente para uma relação social particular e para uma construção social geral. Nelas, do ponto de vista jurídico, o trabalho estaria reduzido ao trabalho remunerado, isto é, ao conjunto de atividades que entram no contrato de trabalho e que são executadas em condições espaciais e temporais estabelecidas pelo capital (Terssac e Maggi, 2004).

O que costumamos chamar de trabalho é uma produção da modernidade que se generalizou com o capitalismo industrial. Para explicar esse processo, André Gorz (1987) vai até os gregos, onde as atividades que constituíam a vita activa podiam ser distinguidas em labor, trabalho e ação. $\mathrm{O}$ labor dizia respeito à sobrevivência física do corpo, manutenção da vida e da espécie humana. Nele, tudo o que é produzido é destinado ao consumo imediato e, talvez por isso, menosprezado, não glorificado, pertencente ao reino das necessidades. O trabalho, também chamado de poièsis, é a atividade correspondente ao artificialismo da vida humana, depende das mãos do homem, de sua criação, inovação, expressão de si. Com as mãos, o homem fabrica todas as coisas que o rodeiam e que constituem o seu mundo. Por fim, a ação, ou práxis, se exercia diretamente entre os homens gregos sem a mediação das coisas ou da matéria. Ela não produz objetos, mas reflexões, ensinamentos, relações.

O conceito moderno de trabalho, segundo Gorz (1987), reúne em uma mesma realidade o labor e o trabalho, que eram distintos entre os gregos, provocando uma simbiose e gerando algo para além dessas distinções antigas, que, ao ser submetido a uma racionalização econômica, cria a ideia moderna de trabalho: o emprego.

Portanto, como já apontava Marx (1974), o trabalho como atividade especificamente humana, capaz de criar novos objetos e também novas relações entre os homens, é o processo através do qual o homem transforma a natureza, os outros homens e a si mesmo, tendo em vista construir as condições necessárias à sua sobrevivência, não apenas como indivíduo, mas também como humanidade. O trabalho incorpora também a dinâmica do vir a ser, pois, ao produzir as condições de sua existência, o homem produz-se a si mesmo, elabora conhecimento e faz história.

O capitalismo moderno, centrado na valorização de grandes massas de capital fixo material, é rapidamente substituído por um capitalismo pós-moderno centrado na valorização de um capital chamado de imaterial, humano ou do conhecimento. O trabalho de produção material, abstrato 
simples, mensurável em unidades de produtos por unidades de tempo, segundo Gorz (2005), passa a conviver com um tipo de trabalho complexo, imaterial, no qual esses padrões clássicos de medida não são facilmente aplicáveis. Nele, o trabalhador não se apresenta mais como aquele que possui - e vende - a sua força de trabalho, canalizada por capacidades predeterminadas pelo empregador, mas como um produto que continua ele mesmo a se produzir.

Pensar o trabalho na atualidade implica, inicialmente, segundo Schwartz (2008), distinguir três perspectivas que dominam as abordagens acadêmicas. A primeira vertente filosófica, na qual ele se inclui, tem como origem a descrição platônica na apologia de Sócrates. Este, em suas reflexões, fala sobre os homens de profissão: "eu sabia bem, em contrapartida, como fazer para encontrar pessoas conhecedoras de muitas coisas belas entre eles; no qual eu não me enganei: ao contrário, elas conheciam coisas que eu não conhecia e, neste respeito, elas eram mais sábias do que eu" (Sócrates apud Schwartz, 2008, p. 125). Essa forma de considerar a sabedoria dos artesãos, em Platão, faz do 'agir em competência' (techné) uma interrogação, um enigma.

Uma segunda tradição filosófica - que tem Hannah Arendt como um de seus principais pensadores - segue, a partir do pensamento grego, as ideias aristotélicas sobre as atividades humanas. Idealmente, o trabalhar teria quatro causas essenciais: da coisa a realizar, das características da matéria a trabalhar, da encomenda do prescritor e da energia do artesão. Schwartz aponta que o trabalho, dissecado entre essas causas, simplesmente desapareceu como problema, pois essas quatro causas dizem tudo o que dele há para se conhecer:

Tudo o que era o enigma do gesto fabricador, a engenhosidade artesanal, a antecipação industriosa, que havia fascinado discretamente a primeira tradição filosófica de Platão a Diderot, tudo isto desapareceu completamente do horizonte dos cálculos cognitivos-mentais: todo ato de trabalho, recortado em seqüências elementares, não solicita do filósofo nada além do que o enigma do eu levanto o braço (Schwartz, 2008, p. 137, grifos do autor).

Ou seja, a 'dimensão gestionária' do trabalho deixa de ser visível.

Uma terceira tradição nesse encontro da filosofia com o trabalho está ligada aos filósofos da história do século XIX. Principalmente a Marx, nos conceitos de força produtiva, relação de produção, modo de produção. Mesmo reconhecendo que o trabalho concreto é o que diferencia o empenho da atividade humana e que, por isso, 'cultivar trigo não é tecer seda', Marx, como destaca Schwartz, irá desentocar o segredo que se esconde sob a diferença manifesta entre o gesto do lavrador e do tecelão - o trabalho abstrato, o valor de troca: “(...) indiferente ao valor particular dos valores 
de uso, o trabalho criador de valor de troca é igualmente indiferente à forma particular do próprio trabalho" (Marx apud Schwartz, 2008, p. 142).

Essa ideia de indiferença, resultado do conceito de valor abstrato, é para Schwartz a demonstração de como todo esse movimento inaugurado pelos escritos de Marx acabou por desenvolver efeitos ambivalentes:

(...) eminentemente positivos (o trabalho elevado à dignidade de um grande objeto intelectual), mas também freqüentemente muito negativos (embora isto não seja devido apenas ao marxismo): a filosofia, a cultura, os movimentos sociais de emancipação foram fracamente interpelados pelo enigma antropológico, humanizante, da atividade industriosa (Schwartz, 2008, p. 143, grifos do autor).

Hoje, diante dos resultados históricos de Marx, a tarefa, para Schwartz, não é mais considerar o trabalho de forma abstrata e geral: o trabalho deve ser algo que se expressa em um corpo, com uma temporalidade e em um contexto; o lugar onde se opera uma dialética, onde, de um lado, há o respeito às normas antecedentes e, de outro, há a gestão das dimensões singulares. Portanto, não redutível à repetição de gestos inconscientes, que levariam à perda da dimensão da inteligência investida a que todo ato de trabalho, por mais parcelado que seja, sempre pressupôs dos trabalhadores, especialmente hoje. Ao tratar da rígida organização científica do trabalho, o taylorismo, Schwartz nos coloca a seguinte questão: “será que o projeto e o princípio do taylorismo foram eficazes e realizados da forma que seus iniciadores o desejavam?" (Schwartz e Durrive, 2010, p. 39). E prossegue a reflexão destacando que é na distância entre os projetos do taylorismo e as realidades concretas que encontramos o que chamamos de atividade. Mesmo nos dispositivos tayloristas, onde parece que tudo foi concebido anteriormente, há um mínimo de gestão de microvariabilidades que escapa à predeterminação, "de certa maneira trata-se de algo que deve escapar sempre e por todo lugar" (Schwartz e Durrive, 2010, p. 39). Estamos diante de algo enigmático: a atividade humana.

Este estudo se insere nessa perspectiva, que considera que em toda atividade há a tentativa de recriação do meio de trabalho, de acordo com as normas de vida de cada pessoa ou coletivo, ou seja, há um debate de normas vivenciado pelos trabalhadores, implicando renormatizações parciais (Schwartz, 2000b). Perspectiva da ergologia, que em seu desenvolvimento teve a influência decisiva da ergonomia da atividade, com os conceitos de trabalho prescrito e trabalho real, cunhando o conceito de atividade, que se apresenta como uma orientação estratégica na busca de articular pesquisa e intervenção sobre o processo de trabalho (Brito, 2004).

Assim, a partir da perspectiva ergológica, especificamente da ideia da 'dimensão gestionária', desenvolvida por Schwartz (2000b), buscamos 
apreender os diversos debates de normas e os valores praticados pelos trabalhadores no cotidiano do trabalho de teleatendimento.

\section{A perspectiva ergológica e a saúde}

Para apreender a complexidade da atividade, a perspectiva ergológica se interessa pelo 'trabalho real', pelo vivido em situação de trabalho. Conhecer o trabalho, compreender sua história e apontar tendências é a questão central da obra de Yves Schwartz. Ou seja, o que sabemos e podemos conhecer do trabalho de homens e mulheres, daquilo que fazem, daquilo que sofrem, daquilo que vivem no cotidiano. Buscar compreender como essas tendências gerais vão se concretizar na realidade nos remetendo ao que as pessoas fazem da vida no trabalho. Entender o trabalho não como objeto, mas como 'matéria estrangeira', pois, como afirma Schwartz, compreender como se vive no trabalho é compreender como nos constituímos e nos desfazemos (Schwartz e Durrive, 2010).

A partir dessa perspectiva, utilizamos os conceitos de 'normas antecedentes' e 'renormatização'. As normas antecedentes são construções históricas e indicam valores consolidados. A ergologia entende que a atividade não é só ação, mas também convocação permanente da subjetividade, utilizada para 'renormatizar' o meio, sendo o imprevisto o seu elemento motor. $\mathrm{Ou}$ seja, a perspectiva ergológica busca encontrar em cada circunstância de atividade um núcleo de 'renormatização' (Schwartz, 2000a).

Na constatação de que o meio de trabalho é sempre variável e imprevisto - portanto, de alguma forma infiel - e de que são os trabalhadores que devem dar conta dessa infidelidade, Schwartz afirma que é necessária uma mobilização das capacidades e dos recursos para além das escolhas a serem feitas, sempre deixando de ser uma mera execução, mas um uso de si. A forma como essas escolhas se processam é sempre pessoal e implica um debate de normas e valores. Quando Schwartz afirma que trabalho é uso de si, quer dizer que também é o lugar de uma tensão problemática, de um espaço de possibilidades sempre a se negociar. É o indivíduo no seu ser que é convocado de forma singular, é requisitado em recursos e capacidades infinitamente mais vastos que a tarefa cotidiana requer, mesmo que não seja visível. Esse conceito de infidelidades do meio, oriundo da concepção de saúde de Canguilhem (1990), considera que singular também é o limiar entre a saúde e a doença.

Sendo assim, saúde implica poder desobedecer, produzir ou acompanhar uma transformação. Ela pode até significar um desvio das normas sociais. Já o patológico é a perda dessa capacidade normativa, a impossibilidade de mudança nas situações onde há algum sofrimento. Nesse meio 
imprevisto e infiel, é preciso renormatizar as condições e o meio de trabalho, tentando contornar os problemas e, de certa forma, administrar as variabilidades que se apresentam. Como afirma Schwartz (2004), a necessidade de gerir essas infidelidades leva a um uso e não à execução; é gerindo essas infidelidades que se pode viver.

E gerir o trabalho significa fazer escolhas, 'renormatizar', criar novas regras em situação. Gerir sendo entendido em um sentido complexo, em uma dimensão profissional, econômica, intersubjetiva e pessoal, onde as 'renormatizações' serão realizadas a partir de valores (Schwartz, 2004). Dessa forma, "cada ser humano (...) tenta mais ou menos (...) recompor um pouco o meio de trabalho em função do que ele é, do que ele desejaria que fosse o universo que o circunda" (Schwartz e Durrive, 2010, p. 31).

A atividade de trabalho fica assim intimamente relacionada com a saúde quando entendemos que a saúde não é mero equilíbrio ou capacidade adaptativa, mas a capacidade de instaurar novas normas, a forma com que interagimos com os eventos da vida, ao longo da nossa existência (Canguilhem, 2001). E nossa capacidade de resistir ou de ficar doente está intimamente relacionada à qualidade das relações de trabalho. A saúde não é um estado natural, mas uma construção intencional na qual o trabalho ocupa lugar importante.

De maneira mais ampla, toda atividade é retrabalho das normas e, portanto, fonte de novos saberes, 'em gestação', à espera de serem mobilizados. Ou seja, a atividade consiste em um debate de normas, em uma atualização das normas antecedentes através do modo como, na ação, cada sujeito reelabora o seu fazer em diversos usos de si. Portanto, a situação de trabalho é um conjunto de meios físicos, de objetos materiais e simbólicos, de sujeitos humanos, de tecnologia e de organização, mas também o resultado de escolhas organizacionais referindo-se aos objetivos e aos meios para atingi-los: as escolhas de ação, a realização das ações relativas a sujeitos específicos, aos meios, aos objetos, às técnicas (Terssac e Maggi, 2004).

Schwartz propõe, a partir da perspectiva ergológica, uma análise que contemple a dialética do geral e do singular, que obriga colar permanentemente o micro e o macro, a partir do momento em que aponta para o fato de que toda atividade de trabalho encontra escolhas, debates de normas e, logo, há encontros de valores onde a história é construída, pois não é a grande história que sobrevoa a vida modesta das pessoas que trabalham: os níveis microscópicos e macroscópicos da vida social se interpenetram (Schwartz e Durrive, 2010).

Dessa forma, utilizamos a perspectiva ergológica desenvolvida por Schwartz (2000b) para sustentar nossa compreensão especificamente no trabalho em teleatendimento. No curso da atividade, ocorrem diversas formas de microgestão, em uma tensa relação entre valores e normas que cir- 
culam na situação concreta de trabalho, desses 'usos de si - por e para si e para outros'. Essa 'dimensão gestionária' intervém diretamente no processo saúde-doença, configurando-se a relação de imanência entre os processos de trabalho, saúde e subjetivação.

\section{Metodologia}

Para compreender a atividade dos trabalhadores no teleatendimento, realizamos entrevistas individuais com as técnicas de Instruções ao Sósia e Encontros sobre o Trabalho. O método de Instruções ao Sósia foi desenvolvido por Ivar Oddone no âmbito do movimento operário italiano (Oddone, Re e Brianti, 1981) durante os anos 1970, em um conjunto de seminários de formação dirigidos aos trabalhadores das indústrias Fiat em Turim. Yves Clot (2006), no início dos anos 1990, recupera esse método, aperfeiçoando-o. Na execução de uma Instrução ao Sósia, a atividade do 'sósia' consiste em resistir à atividade do trabalhador que, ao dar suas instruções, naturalmente impõe sua versão do que ocorre. Dessa forma, esse dispositivo permite que a imagem do trabalhador se duplique: o sósia possibilita a visualização das práticas, das estratégias, das representações dentro da lógica de expertise, pois o trabalhador é expert naquilo que faz (Magnier, 1999).

O objetivo dos Encontros sobre o Trabalho, de acordo com Durrive (2010, p. 309), é "multiplicar os lugares de debate sobre a atividade, porque eles são reservatórios inimagináveis de energia para a formação e o desenvolvimento, individual e coletivo". Ou seja, "tomar consciência da renormatização permanente de que somos autores, da aventura que nos é própria a cada vez que entramos em atividade para realizar uma tarefa, pode ter consequências decisivas".

Nesta pesquisa, os Encontros sobre o Trabalho ocorreram na sede do Sindicato dos Trabalhadores em Telecomunicações do Rio de Janeiro (Sinttel-RJ), localizada em Miguel Pereira, durante dois dias, tendo a participação de 33 operadores(as). Foi favorecido o debate sobre a relação saúde-trabalho, com o objetivo de os(as) trabalhadores(as) elaborarem e construírem discursos, individual e coletivo, sobre sua atividade, apropriandose mais de suas experiências. Procurou-se estabelecer um diálogo entre dois universos de conhecimento: o técnico-científico e o da experiência, dos saberes constituídos e dos saberes investidos. No debate sobre a atividade, em que o trabalho real é foco da discussão, criou-se a possibilidade para novas compreensões e entendimentos, a partir das descrições e das falas, que muitas vezes não são claras nem mesmo para os envolvidos.

Fizemos uma discussão sobre o conceito de saúde, ressaltando a importância do diálogo nos coletivos de trabalhadores possuidores de um 
saber específico e necessário para detectar, interpretar e transformar as condições nocivas de trabalho. O diálogo pode fornecer elementos para a melhor compreensão e possível transformação dos problemas e das diferentes formas de mal-estar vivenciadas no cotidiano de trabalho. Mostramos a importância de nos apropriarmos de um outro conceito de saúde, que não seja por negação, pela ausência de doença, mas pela capacidade de enfrentar individual e coletivamente as adversidades do meio e transformá-lo segundo nossos anseios e necessidades. Enfatizamos a importância de colocarmos em palavras as experiências, o que cada trabalhador imprime de si na atividade, para que esse conhecimento, esse saber, seja utilizado a seu favor. Além disso, apresentamos resultados de alguns estudos científicos sobre a saúde e o teleatendimento, além do conteúdo do Anexo 2 da Norma Regulamentadora 17 do Ministério do Trabalho e Emprego, que trata especificamente do trabalho de teleatendimento.

Realizamos discussões em dois grupos, colocando questões sobre a atividade para disparar o debate. Esses grupos, compostos por 15 operadores e operadoras, possuíam um coordenador de debates. Em apenas um deles, realizamos a gravação para posterior análise. O debate procurou compreender e gerar conhecimento sobre a atividade na perspectiva de transformar os processos que levam ao sofrimento e à doença, dando visibilidade às questões e formulações dos(as) operadores(as) para servirem de parâmetros para reflexão e ação do sindicato.

\section{Resultados}

Destacamos aqui algumas reflexões e análises sobre o trabalho de teleatendimento, considerando que a atividade tem sempre algo de não previsto em sua potencialidade por ser 'microrrecriadora'. Como a atividade é o centro de uma dialética entre o impossível e o 'invivível', exige sempre uma gestão (Schwartz e Durrive, 2010). Toda gestão do trabalho, segundo Yves Schwartz (2010), se desloca em um espaço de três polos: o mercantil, o do direito e o da atividade. Um esquema bipolar não expressa as matrizes de tensão, as matrizes de história, nem deixa claro por quem são vividos os conflitos entre os dois polos - o mercantil e o do direito - e quais as circunstâncias dessa vivência. É no polo da atividade que se dão as 'dramáticas do uso de si', dos debates de normas e valores, as gestões do e no trabalho.

Dessa forma, o trabalho não possui - ou produz - apenas um valor. Em nossa sociedade de mercado e direito, há o debate de pelo menos três tipos de valores: mercantil, do direito e da atividade. Esses valores que se crista- 
lizam em cada polo têm temporalidades próprias e, portanto, pode-se falar de 'tempos-valores' específicos.

No caso do teleatendimento, as contraposições entre valores de mercado (valores dimensionáveis) e valores sociais e pessoais (valores sem dimensão), que os trabalhadores devem considerar e corresponder no atendimento, criam contradições que atuam sobre as 'dramáticas de usos de si'. Como resultado, surgem distorções, impedimentos e ambiguidades que se refletem como sofrimento, medo, adoecimento, em paralelo à criação, ao desenvolvimento e à reinvenção permanente de normas.

A 'dimensão gestionária' do trabalho no teleatendimento se expressa na economia do corpo dos(as) operadores(as) antes, durante e após a jornada de trabalho. Antes, quando ainda se está em casa na preparação para ir ao trabalho. Durante, com o apoio dos colegas, onde a cooperação se manifesta para o enfrentamento dos momentos críticos. E depois, no esforço de não levar para casa angústias e problemas vivenciados no trabalho.

Antes

Você já sai de casa se preparando. (...) Você vai pensando assim: tomara que não tenha um cliente chato, tomara que a coisa vá numa boa. Então, vai depender muito do que você está vivendo antes de ir para lá, porque você sabe que vai chegar lá e vai lidar com a ira dos outros, muitas vezes com a angústia, com a ansiedade... Você vai torcendo por qual tipo de cliente quer que ligue. Eu ia tentando o mais calmo possível. (Op. 1)

Durante

A primeira coisa que faço é orar, para Deus me dar apoio. Pensar que não é porque a pessoa que está do outro lado está me xingando e fazendo um monte de coisas que eu vou me estressar. Você tem que estar ali e manter a calma, falando com você mesma: não posso me estressar. Eu trabalhava na base do calmante. Percebi que tinha de lidar com isso. Então o assinante vai falando e eu não vou deixar me adoentar, porque, se você absorver aquilo, prejudica sua saúde, você fica doente. (Op. 5)

Se você pegar a primeira ligação, segunda e terceira tranquilas, você até vai tranquila o resto do dia. Mas se você, de primeira, pegar uma ligação estressante... é complicado. Você está ali atendendo, o cliente está te enervando, você já está tremendo. Teve uma vez que eu fiquei tão vermelha que fui parar no médico para tomar um calmante. Aí, um ajuda o outro nessa hora... Isso é que é bom, acalma... (Op. 2) 
Depois

Ir para casa e tentar não deixar aquelas coisas que te aconteceram lá no serviço. Ir pensando em outras coisas até chegar em casa e tirar aquilo da sua cabeça. Porque, senão, você leva para dentro de casa. Já saí de lá superestressada, cheguei em casa, meu esposo falou qualquer coisa e eu estourei, porque estava com aquela carga toda em cima de mim. (Op. 5)

Quando eu pego pessoas ignorantes, que xingam, gritam, eu fico muito sem dormir. Eu procuro não levar o problema do trabalho para minha casa porque senão fica tudo pior. Mas às vezes não tem jeito. Na maioria das vezes, não tem jeito. (Op. 4)

A análise da atividade, do 'trabalhar-gerir' segundo Schwartz (2004), mostra-se importante na medida em que reconhece a variedade de níveis imbricados e o engajamento subjetivo, onde há escolhas a serem feitas. Apesar de essas escolhas acontecerem em microssituações, elas se referenciam a dimensões sociais mais amplas. As regras do mercado são reprocessadas pelos operadores na busca de uma economia do corpo, para a saúde, com a criação de outro uso das prescrições: das pausas, do script, da voz.

Outro uso da audição

Estratégia número um é mute [mudo]. Depois de um momento, por gentileza, mute. Aí, quando você fala: só mais um momento, por gentileza, mute. Aquilo vai cansando e o operador acha que a qualquer momento a pessoa vai bater o telefone, e pronto. Bateu o telefone, ufa! Foi embora, vai cair em outro. Essa é uma [estratégia], a outra é ficar ligado no script... É fazer com que de repente o cliente desligue. Ele desligou, ah, que alívio... Essas são as estratégias (...). O atendente tem que ter essas manhas... (Op. 1)

Por dentro, eu ficava: ai, meu Deus, me dá paciência, ou então coloco no mudo e respiro... É difícil... (Op. 4)

Outro uso das pausas

Muitas vezes, com esse horário de seis ao meio-dia, eu acabo saindo meio-dia e almoçando depois desse horário. Então, não uso meus 15 minutos para nada, eu acabo dividindo. Tiro meus 15 minutos partido durante o dia. Quando a supervisora puxa o relatório, ela não vê que eu parti, que eu tirei esses 15 minutos divididos. Ela só consegue se, enquanto eu estiver tirando a pausa, entrar no sistema e monitorar. (Op. 3) 
A maioria faz isso. Até para você descansar um pouco mais porque você está lá numa ligação estressante, pensando: eu ainda não tirei minha pausa para o lanche, mas ainda não está na minha hora. E se ela [a supervisora] está lá sentada, não está circulando, dá a pausa de uns três, quatro minutos. Isso já dá um alivio. Dá a pausa, fica ali no PA [Posto de Atendimento] e dá uma relaxada, conversa com colega ou entra na Internet, dá uma olhada em alguma coisa e aí pronto. Daqui a pouco eu volto e vou controlando o tempo, depois coloco disponível de novo ou se ela [a supervisora] voltar a se sentar. (Op. 7)

Outro uso da voz

Já levei muita ligação só na entonação da voz. Eu sempre fui educadíssima com cliente. O cliente fala assim:

- Ah! não sei o quê, não sei o quê...

- Senhor! Isso é assim.

E ele está falando, falando e falando. Aí, na educação:

- Senhor, por gentileza, assim... Posso? Pois não, senhor.

A minha entonação (...) é mais que uma facada. E o cliente:

- Entendi. (Op. 6)

Eu já aprendi diferente. Se o cliente estiver falando muito alto, eu vou falando mais baixo. Ele vai gritando e eu vou falando mais baixo. Eu chego a falar tão baixo que ele não entende o que eu estou falando. Então, ele é obrigado a calar a boca para poder ouvir. (Op. 9)

A variação vocal permite a expressão da subjetividade dos(as) operadores(as). Apesar do rígido controle, os(as) operadores(as) conseguem imprimir a marca de sua identidade no discurso (Algodoal, 2002). Dessa forma, conjugam a economia de si com padrões que julgam mais eficazes. O uso da voz torna-se ainda mais importante, uma vez que os(as) operadores(as) estão privados(as) da utilização de informações gestuais, ficando restritos(as) ao ajuste pelas palavras, pela voz (Souza e Silva, 2002).

O controle rígido do comportamento, da fala e do tempo, somado às variabilidades do relacionamento com o público, são, segundo Silva e Assunção (2005), motivos de acentuação da carga de trabalho na medida em que diminuem as alternativas operatórias perante as variáveis das situações de trabalho.

Existem excessos, às vezes, nessas prescrições de atendimento... Há uma bitolação da parte da gestão, da parte administrativa quanto a isso. Porque a empresa impõe que vai ser assim o script. Tudo bem. Mas eu vou chegar para o cara que está xingando a minha mãe, xingando a minha família, e falar o que está previsto. 
O problema do atendimento é complicado, porque a pessoa [que] está ali no atendimento incute tudo. (Op. 10)

Como eu falei, tem as pessoas educadas e tem as ignorantes. Às vezes, a pessoa pede um teste e a gente faz o procedimento e vê que a pessoa não tem direito ao crédito que ela quer. Então ela xinga a gente, xinga a mãe, manda para tudo quanto é lugar e a gente tem que ficar sem ter o que falar. Não pode debater com o cliente, não pode falar nada, mesmo sendo o cliente educado ou não. A gente tem que seguir o procedimento da empresa. (Op. 4)

Nós temos cobrança. Por exemplo, no produto em que eu trabalho, que é a X.com, nós fazemos o atendimento on-line. Então, quando o cliente liga, nós temos aquele script que quase ninguém usa. Mas aí você escuta o supervisor gritar: tem que fazer. E fica aquela pressão psicológica. Está vermelho o quatro, tem que ficar verde. E fica aquilo... Então a gente fica ali estressado realmente, trabalhando na pressão que eles fazem. E, no princípio da ligação, você já tem que dizer: esse mês é mês de aniversário da X.com, por isso ela tem muitas promoções. E você não pode esquecer, porque isso vale pontuação. (Op. 8)

(...) acho que o script poderia ser um pouquinho mais aberto. A gente não pode desligar, tem que ficar com o assinante até ele desligar. Não podemos desligar, não podemos fazer certos tipos de transferências. Então, realmente é uma coisa difícil. (Op. 5)

O debate sobre o prescrito e o real revela que tanto o excesso como a falta de prescrição têm efeitos danosos para aqueles que trabalham. É um grande constrangimento para os(as) operadores(as) terem de ficar presos ao script, na maioria dos casos, inadequado. Na busca de conciliar objetivos, às vezes contraditórios, a organização do trabalho mobiliza os trabalhadores como principal fonte de produtividade, de qualidade e de adaptabilidade dos sistemas. Dessa forma, os trabalhadores encontram-se ao mesmo tempo diante de um excesso ou de falta de prescrições.

Por isso, pressupomos que a participação dos envolvidos na elaboração das normas e dos procedimentos, essa construção conjunta, é fundamental e pode evitar descompassos na execução das tarefas, possibilitando também uma maior eficácia. Não ignorar a experiência de quem está atuando é possibilitar um trabalho mais 'vivível', pois é completamente diferente um script, uma orientação construída a partir desse coletivo, que conhece dimensões às vezes ocultas, do que aquele formulado externamente a esse. Porém, as próprias gerências e supervisões poderiam otimizar as prescrições existentes, fazendo um uso local e adequado às situações. 
Eu acho que todo mundo acabou chegando a um consenso de que está havendo excessos e não há uma mobilidade, uma flexibilidade local do que é feito. Por exemplo, pode ser uma rigidez no script, no caso de o cliente ligar para reclamar e você começar a oferecer produtos. Então, apesar de ser cada um com seu produto de empresas diferentes, no final é quase a mesma coisa, todo mundo reclamando da mesma coisa. Existem excessos, às vezes, nessas prescrições de atendimento... (Op. 10)

Entre as prescrições e os clientes, existe todo um trabalho de 'renormatização' das tarefas e de reformulações discursivas que dão sustentação a um investimento pessoal constante, inclusive para responder ao que não está previsto pelo prescrito e, nessa zona de incerteza, realizar a atividade na busca de sua eficácia.

Tem lá qual é a forma de atender, tem script de atendimento, todo o procedimento... Desde a hora em que você se loga no sistema até a hora em que sai. Então, é um monte de detalhes quando você está atendendo... Se você está com uma pessoa estressada, o excesso da prescrição atrapalha. Então, na hora em que está falando com a pessoa, você pensa em se colocar à disposição para atender aquela pessoa da melhor maneira possível, para você poder alcançar a meta. (Op. 4)

Para dar conta das infidelidades, dos imprevistos, as escolhas são necessárias porque as instruções contêm equívocos ou são insuficientes para lidar com as variabilidades e o acaso. A maneira de lidar ou cobrir esse déficit de normas será sempre uma maneira pessoal, uma tentativa de recompor o meio em torno de sua própria história, normas e valores (Schwartz, 2000b).

Existem coisas assim, de uma pessoa receber uma ligação e no meio dela começa a chorar. Isso vai pingando, você sente que as pessoas entram calmas e saem irritadas, mal-humoradas. (Op. 1)

Então isso é uma carga. Você lidar diariamente com isso é complicado. Deveria ter um suporte. Ter, dentro do ambiente de trabalho, uma equipe responsável por lidar com aquela pessoa. Ou seja, às vezes, você vem de casa já com certa carga emocional, já vem fragilizado, dependendo da sua relação... Aí você entra no ambiente de trabalho com a autoestima lá embaixo. Como é que você quer que uma pessoa esteja motivada, como é que você vai querer que uma pessoa reverta determinadas situações, se ela mesma não consegue. Você vai ter problemas... Tendinite, problemas vocais, uma série de problemas... Aquele trabalhador começa a adoecer e é substituído automaticamente. Então, existe a rotatividade. (Op. 2)

A construção do saber no e do trabalho, da estocagem de certo número de formas de competências, exige um tempo. No entanto, essa estocagem é 
pouco permitida pelas precárias condições de trabalho, que expulsam os trabalhadores e as trabalhadoras da atividade. A alta rotatividade é uma característica desse setor, assim como seu elevado índice de adoecimento.

Depois de quatro anos, o cliente, quando fala comigo, eu já sei o que ele quer. Voltou o comprovante, eu já peço o resumo de vendas, já abro na página certa, já vou abrindo a solicitação para pedir o reprocessamento. Então, para mim, é fácil. Mas para uma pessoa que não conhece.... E cada cliente é um cliente. Tem cliente que quer só trocar o telefone, alterar o telefone lá no sistema, e te enseba, te enseba, te enseba, te enche o saco... E o atendimento, que era para levar quatro segundos, dura às vezes um minuto e quarenta. (Op. 2)

Muitas vezes, se você é rápido, como a gente... Esses macetes a gente vai pegando com o tempo. Você sabe que vai dar tempo de registrar a chamada anterior antes que entre a próxima ou já vê que está com fila, porque na hora em que está com fila o supervisor fica lá dentro para ver se você não fica de pausa padrão, que é a pausa em que não entra ligação e você perde produtividade. Porque o ideal é: você terminou uma, bota disponível; terminou outra, bota disponível; para entrar ligação o tempo todo e não se formar fila. Você já pensou se a cada ligação que eu atendo eu travar meu telefone para não entrar, e se o colega fizer a mesma coisa, e se o outro também fizer a mesma coisa? Vai ficar uma fila porque ninguém está atendendo, mesmo que seja em poucos segundos. Naqueles segundos já está entrando outra ligação e outra ligação. (Op. 4)

É nessa dinâmica que as competências se realizam, na capacidade dos operadores de, além de controlarem o Tempo Médio de Atendimento (TMA) - que varia de acordo com a empresa -, atenderem os clientes e registrarem adequadamente o seu atendimento. Para que o trabalho se realize, é preciso não apenas os procedimentos e os regulamentos, mas é necessário que os trabalhadores renormatizem, que transgridam, recriando a atividade, como no caso descrito a seguir pelo operador, no qual ele deve decidir entre manter seu TMA e o script ou melhorar a qualidade do atendimento, prestando um serviço ao cliente. É paradoxal solicitar aos operadores que assumam riscos e formulem engajamentos de tomada de responsabilidade sobre objetivos tão estranhos a eles. O sofrimento vem dessa necessidade contraditória, não de uma ausência completa ou de uma negação da iniciativa, mas do fato "de que tal iniciativa é ininterruptamente recontrolada, limitada, contradita ou se desenvolve com uma limitação importante de meios" (Zarifian, 1998, p. 27).

Você é punido por coisas bobas e que não afetam o seu atendimento. Eu tirei 63 em uma monitoria porque o cliente já tinha ligado quatro vezes e eu fui e veri- 
fiquei. O problema dele não era nada do que as pessoas estavam falando. Ele não conseguia fazer uma ligação e, quando eu fui ver, abriram vários pedidos para a área técnica verificar o problema dele. Só que o problema dele era uma programação que se faz no telefone (...). Quer dizer, há uma mentalidade aí, porque seu setor é cobrado por um outro que é cobrado por um outro e eles só querem ver a parte prática. É muito prático para eles te monitorarem, ouvirem sua ligação, te pontuarem igual a um robô naquilo que está ali. Porque eles não precisam pensar, eles não precisam perder tempo, eles não ficam achando dentro daquele parâmetro lacunas que existem, por exemplo, se não falou o nome do cliente ou então não soube verificar a ferramenta de trabalho, que é a Intranet. (Op. 4)

Nessa dramática do uso de si apresentada pelo operador, fica expresso o debate de valores, pois ele aponta uma prescrição que considera inatingível. Isso porque, na busca de prestar um serviço, evitando que o cliente mais uma vez retorne a ligação sem ser atendido na sua necessidade, acaba por não se restringir às prescrições (falar três vezes o nome do cliente, observar o TMA etc.) e, consequentemente, ser punido na avaliação.

Eu perdi ponto porque meu atendimento médio foi maior. Eu perdi ponto porque eu não chamei o nome dele no meio da ligação. E no final (...) perdi ponto porque (...) não falei obrigado por aguardar. E tirei 63. Mas sabe o que ele falou no final para mim?

- Obrigado, eu estou há quatro dias com esse problema e só ficam abrindo chamada para técnica e você resolveu. Muito obrigado!

Quer dizer, ele não vai ligar mais, ele não vai gerar outra chamada, outra ligação. E eu tirei 63. Aí fui falar com a minha supervisão: “Puxa, eu tirei 63, mas, para mim, foi cem porque você escutou o que o cliente falou no final. Para mim, foi cem. (Op. 4)

O sistema de avaliação das empresas de teleatendimento inicia seu processo avaliativo em $100 \%$ (ou seja, zero erro), no qual qualquer erro é um desvio desse padrão idealizado para menos. O operador questiona essa lógica alegando que, em outras situações da vida em que se é avaliado, o foco da avaliação parte do zero e se concentra nos acertos. Está aí outra contradição fundamental: a norma que rege a organização do trabalho busca apontar e contabilizar os erros dos operadores de tal forma que seus acertos e suas competências jamais sejam reconhecidos. Para as empresas, a norma é não errar, de acordo com os valores mercantis/mensuráveis nos quais se baseiam; para os trabalhadores, a norma seguida é procurar acertar, em consonância com valores sem dimensão, do bem comum (Schwartz e Durrive, 2010).

Isso é uma loucura! E, como eu falei, é começar uma prova ganhando dez e o professor ficar procurando erro para poder te tirar ponto. Isso não existe. Você vê, 
uma ligação que é cem, você acerta tudo, e eles dão um jeito de ficar procurando besteira para você ficar com pouco ponto. (Op. 4)

Como o essencial do trabalho pertence ao mundo da subjetividade, ao mundo invisível, a avaliação é uma questão delicada. Não se avalia o invisível. A eficácia do trabalho depende da criatividade e do envolvimento do trabalhador. A competência se manifesta na capacidade de decidir, empiricamente, em situação concreta e imediata, entre, por exemplo, aumentar o fluxo ou melhorar a qualidade do serviço. A mobilização da subjetividade necessária para lidar com a situação, para conseguir inventar uma saída e se manter íntegro apesar das restrições, é o verdadeiro enigma do trabalho como explicita Jobert (1999).

Outra questão é a imagem do operador, reforçada pela mídia, associada à ideia de um trabalho sem qualificação, robotizado, sem compromisso com o público, por estarem, os operadores, presos ao script e às restrições da própria organização do trabalho. Na verdade, o cliente não 'vê' claramente o trabalho deles. Além da hierarquia, os clientes também não reconhecem o engajamento dos operadores, desequilibrando o eixo polo do mercado-polo político, favorecendo ao mercado no que tange à legitimação da precarização dessas relações de trabalho, colocando assim em foco a questão da dignidade do trabalho como valor sem dimensão. O operador, na fala a seguir, identifica que a não compreensão da complexidade da atividade dificulta as ações políticas de defesa desses trabalhadores, fragilizando as negociações salariais, de melhorias das condições de trabalho, e a possibilidade de fortalecimento do coletivo dos trabalhadores.

Outra coisa é a visão que o público tem do atendente do call center, do atendimento do telemarketing. Existe uma depreciação. Esse programa humorístico que tem um personagem que é uma atendente que faz chacota, que está atendendo fazendo unha, isso nunca acontece no call center. (...) Jamais acontece da forma como esse programa é colocado (...). Então, todo mundo acha que call center é isso, uma bagunça... Fazem uma brincadeira com uma categoria e, se ela não se manifesta, na realidade está de acordo. (Op. 1)

Então, você pode mudar a imagem do operador colocando esse operador como uma pessoa que gosta de fazer o atendimento. Quer dizer, às vezes ele não tem condições adequadas, às vezes ele não está com meios adequados, mas é um operador que gosta e você vai mudando a imagem. Então, isso é importante para a gente também. Conseguir vincular esse tipo de informação, porque muda muito. Eu acho que, por que o que a gente tem na opinião pública [é] assim? Por que isso? Primeiro porque as pessoas ficam irritadas de ficarem falando com um operador que esta seguindo aquele script. Parece sempre que é o quê? Que é uma 
tapeação, ou seja, o cara está ali porque não tem outro lugar para estar no mercado de trabalho, a única oportunidade que encontrou é o telemarketing. Então, na realidade, a gente também tem que mudar, eu acho que isso é uma coisa importante, que é mudar um pouco esse perfil, esse perfil que na realidade está se configurando porque ele não é isso. (Op. 8)

As rápidas transformações que ocorrem nessa área com o avanço tecnológico acabam se associando a uma desqualificação dos(as) operadores(as). Foi possível verificar como, no início dessa atividade, dominava-se um conjunto de conhecimentos nas várias etapas do processo, inclusive de perfil tecnológico. E em um curto espaço de tempo, com a pulverização desse conhecimento, perde-se essa perspectiva. Com a terceirização das empresas, essa situação se agravou.

A privatização e terceirização de serviço deixou muito a desejar porque a privatização massificou todo o trabalho de atendimento. Não é mais prezado pela qualidade e sim pela quantidade. Então, você nunca é testado pela qualidade, você poderia ser um cara bom naquilo que faz, mas não é isso. É tempo médio, é vender, é isso e aquilo. Não importa se você está fazendo uma venda ou (...) está atendendo errado que ele [o cliente] vai ligar de novo. Mas você andou rápido, você operou fila, você é um número o tempo inteiro. (Op. 4)

Quando era [empresa X], o atendimento era mais personalizado, eles até criaram expressões em inglês, como o report do cliente. Se ele falasse com você todo coloquial, numa boa, você entrava na dele. Se ele era formal, você ia ser formal. Então, chegava a ser um atendimento mais pessoal. Você se sentia bem de falar com o cliente. (Op. 10)

O desenvolvimento do setor deveria permitir explorar o potencial e oferecer um desenvolvimento para os(as) operadores(as). No entanto, o que se tem é a falta de clareza da evolução das atividades que impedem tanto os superiores hierárquicos quanto operadores de pensarem e prepararem percursos profissionais (Zarifian, 2002).

\section{Considerações finais}

Nesta pesquisa, verificamos as três características da atividade apontadas por Schwartz (2005): a 'transgressão', que atravessa o consciente e o inconsciente, o verbal e o não verbal, o biológico e o cultural, o mecânico e os valores; a 'mediação', que nos impõe dialéticas entre todos esses campos, assim como entre o 'micro' e o 'macro', o local e o global; e a 'contradição', lugar de 
debates entre as normas e as tendências à 'renormatização'. Essas 'renormatizações', referendadas por valores, da pessoa e dos coletivos, de suas histórias, relacionam-se intimamente com a saúde, como capacidade adaptativa, inclusive para a instauração de novas normas.

Uma situação apontada como importante constrangimento para os(as) operadores(as) foi o estabelecimento e a cobrança de objetivos contraditórios pelas gerências, que muitas vezes, no caso do teleatendimento, devem oferecer produtos ao cliente enquanto, na realidade, ele liga para fazer reclamações. Como verificamos nos debates de valores expressos pelos(as) operadores(as) que devem gerir o tempo volátil do mercado, do TMA, e atender às necessidades dos clientes. Constrangimentos que são fonte de frustração e sofrimento, impedindo o reconhecimento do trabalho dos(as) operadores(as), rompendo assim com o sentido do trabalho. Constrangimentos que levam ao adoecimento.

A metodologia utilizada tem o lado positivo de, ao possibilitar a elaboração da experiência e a releitura da realidade através do diálogo, permitir uma aproximação consciente das singularidades das situações de trabalho e de suas estratégias. Dessa confrontação de discursos revelam-se os distanciamentos que existem entre a organização do trabalho prescrita e a organização do trabalho real. O diálogo é uma ação sobre a ação que transforma a experiência ocorrida em meio de viver uma outra experiência em que outros engajamentos de si são colocados em vista (Clot, 2006).

Por fim, a perspectiva ergológica indica que reconhecer o que é exigido na atividade proporciona uma capacidade diferenciada de negociação, antecipando-se eficazmente os problemas a serem resolvidos. Na sua singularidade, a 'dimensão gestionária' e as 'renormatizações' devem ser reconhecidas pelos(as) próprios(as) trabalhadores(as), profissionais da saúde e pesquisadores como elemento fundamental para a prevenção dos adoecimentos e para a promoção da saúde.

\section{Notas}

1 Pesquisadora do Centro de Estudo da Saúde do Trabalhador e Ecologia Humana (Cesteh), da Escola Nacional de Saúde Pública Sergio Arouca, Fundação Oswaldo Cruz (Ensp/Fiocruz), Rio de Janeiro, Brasil. Doutora em Saúde Pública pela Ensp. $<$ simone@ensp.fiocruz.br>

Correspondência: Centro de Estudos em Saúde do Trabalhador e Ecologia Humana, Escola Nacional de Saúde Pública Sergio Arouca, Fundação Oswaldo Cruz (Cesteh/Ensp/Fiocruz), Rua Leopoldo Bulhões, 1480, CEP 21041-210, Rio de Janeiro, Brasil. 
2 Pesquisadora do Centro de Estudo da Saúde do Trabalhador e Ecologia Humana (Cesteh), da Escola Nacional de Saúde Pública Sergio Arouca, Fundação Oswaldo Cruz (Ensp/Fiocruz), Rio de Janeiro, Brasil. Doutora em Saúde Pública pela Ensp, com pós-doutorado em Ergologia pela Université d'Aix-en-Provence, França. <jussaradebrito@gmail.com>

\section{Referências}

ALGODOAL, Maria Juliana. As práticas de linguagem em situação de trabalho de operadores de telemarketing ativo de uma editora. Tese (Doutorado em Linguística Aplicada e Estudos da Linguagem) - São Paulo, Pontifícia Universidade Católica, 2002.

BRITO, Jussara. Saúde do trabalhador: reflexões a partir da abordagem ergológica. In: FIGUEIREDO, Marcelo et al. (Orgs.). Labirintos do trabalho: interrogações e olhares sobre o trabalho vivo. Rio de Janeiro: DP\&A, 2004. p. 91-114.

CANGUILHEM, George. O normal e o patológico. 3. ed. Rio de Janeiro: Forense, 1990.

Meios e normas do homem no trabalho. Pro-posições, Campinas, v. 12, n. 2-3, p. 109-121, jul./nov. 2001.

CLOT, Yves. A função psicológica do trabalho. Petrópolis: Vozes, 2006.

DURRIVE, Louis. Pistas para o ergoformador animar os encontros sobre o trabalho. In: SCHWARTZ, Yves; DURRIVE, Louis (Orgs.). Trabalho \& ergologia: conversas sobre a atividade humana. 2. ed. Niterói: EdUFF, 2010. p. 309-318.

GORZ, André. Adeus ao proletariado: para além do socialismo. 2. ed. Rio de Janeiro: Forense-Universitária, 1987.

O imaterial: conhecimento, valor e capital. São Paulo: Annablume, 2005.

JOBERT, Guy. A inteligência no trabalho. In: CARRÉ, Philippe; CASPAR, Pierre. (Orgs.).
Tratado das ciências e das técnicas da formação: horizontes pedagógicos. Lisboa: Instituto Piaget, 1999. p. 223-239.

MAGNIER, Jacqueline. Le travailler et son double. Les territoires du travail, n. 3, p. 53-59, 1999.

MARX, Karl. O capital. v. 1. 2. ed. Lisboa: Delfos. 1974.

ODDONE, Ivar; RE, Alessandra; BRIANTI, Gianni. Redécouvrir l'expérience ouvrière: vers une autre psychologie du travail? Paris: Messidor/Editions Sociales, 1981.

SCHWARTZ, Yves. A comunidade científica ampliada e o regime de produção de saberes. Trabalho \& Educação, n. 7, p. 38-46, jul./dez. 2000a.

Le paradigme ergologique ou un métier de philosophe. Toulouse: Octarés Editions, 2000b.

Circulações, dramáticas, eficácias da atividade industriosa. Trabalho, Educação e Saúde, v. 2, n. 1, p. 33-55, 2004.

Actividade. Plur(e)al, vol. 1, n. 1, p. 63-64, 2005. Disponível em: <http://plureal. up.pt/revista/artigo.php?id=37t45nSU5471 12245:2:383381>. Acesso em: dez. 2006.

Le travail dans une perspective philosophique. Revue Ergologie, v. 0, p. 121-154, 2008. Disponível em: <http://sites.univprovence.fr/ergolog/Bibliotheque/Ergologia/ Numero_0//Ergologia_0_YvesSchwartz.pdf $>$. Acesso em: 12 out. 2009. 
. O homem, o mercado e a cidade. In: SCHWARTZ, Yves; DURRIVE, Louis (Orgs.). Trabalho \& ergologia: conversas sobre a atividade humana. 2. ed. Niterói: EdUFF, 2010. p. 249-276.

SCHWARTZ, Yves; DURRIVE, Louis (Orgs.). Trabalho \& ergologia: conversas sobre a atividade humana. 2. ed. Niterói: EdUFF, 2010.

SILVA, Airton Marinho; ASSUNÇÃO, Ada Ávila. Negociações sociais para melhoria das condições de trabalho no setor de teleatendimento: o descompasso entre a posição das empresas e a realidade do trabalho. Interface-Comunicação, Saúde, Educação, Botucatu, v. 9, n. 18, p. 553-570, set./dez. 2005.

SOUZA E SILVA, Maria Cecília. A dimensão linguageira em situações de trabalho. In: SOUZA E SILVA, Maria Cecília; FAÏTA, Daniel. (Orgs.). Linguagem e Trabalho. São Paulo: Cortez. 2002. p. 61-76.
TERSSAC, Gilbert; MAGGI, Bruno. O trabalho e a abordagem ergonômica. In: DANIELLOU, François. (Org.). A ergonomia em busca de seus principios: debates epistemológicos. São Paulo: Edgard Blücher, 2004. p. 79-104.

ZARIFIAN, Philippe. Eventos, autonomia e enjeux na organização industrial. In: LEITE, Márcia; NEVES, Magda. (Orgs.). Trabalho, qualificação e formação profissional. São Paulo: Alast, 1998. p. 21-30.

O tempo do trabalho: o tempo devir frente ao tempo espacializado. Tempo Social, São Paulo, v. 14, n. 2, p. 1-18, out. 2002 .

Recebido em 19/01/2011

Aprovado em 25/02/2011 